\title{
Histórico e os limites da reforma agrária na contemporaneidade brasileira
}

\section{History and limits of the agrarian reform in the Brazilian contemporary time}

\author{
Paulo Nakatani* \\ Rogério Naques Faleiros* \\ Neide César Vargas ${ }^{* *}$
}

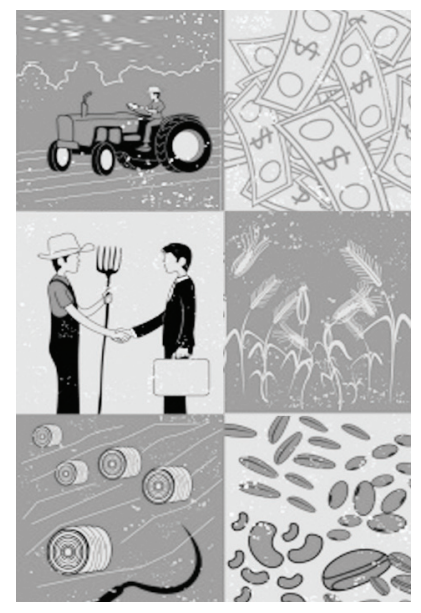

“[...] a acumulação primitiva não se dá apenas na gênese do capitalismo; em certas condições é estrutural e não apenas genética."

Francisco de Oliveira

Resumo: Objetiva-se reconstituir a trajetória da questão fundiária (e agrária) na experiência de maior concentração de riqueza e recursos vivenciada no âmbito do sistema capitalista, partindo-se da premissa de que a crescente desigualdade do modelo brasileiro passa necessariamente pela questão agrária. Num segundo momento, procede-se à análise dos limites atualmente colocados a qualquer possibilidade de uma Reforma Agrária ampla e estrutural, dados pelo avanço do agronegócio nos últimos dez anos, pela desmobilização política de parcela significativa da sociedade no que se refere a esta questão e pelos

* Mestre em Système de L'économie Mondiale - Université de Paris X, Nanterre, doutor em Ciências Econômicas - Université de Picardie e pós-doutor pela Université Paris XIII. Atualmente é professor associado II da Universidade Federal do Espírito Santo, Vitória (ES), Brasil.E-mail: paulonakatani@gmail.com

** Mestre em História Econômica pela Unicamp e doutor em Economia Aplicada pela Unicamp. É autor de Homens do café: Franca 1880-1920 e de Fronteiras do café. Atualmente é professor adjunto da Universidade Federal do Espírito Santo (UFES). É chefe do Departamento de economia da Ufes, e professor do Programa de Pós-Graduação em Política Social _ UFES, Vitória (ES), Brasil.E-mail: rogerionaques@yahoo.com.br.

*** Mestre em Economia pela Universidade Federal Fluminense e doutor em Economia Aplicada pela Universidade Estadual de Campinas. Atualmente é professora associada I da Universidade Federal do Espírito Santo (UFES), Vitória (ES), Brasil. Estuda o governo municipal sob um ponto de vista institucionalista, fazendo incursões no campo da metodologia econômica.E-mail: neide.vargas@uol.com.br. 
próprios limites estruturais da economia brasileira nos quadros da globalização financeira. O texto será dividido em seis sessões: a) colonização e origens do latifúndio; b) O modelo agroexportador e a ruptura incompleta; c) a questão agrária e a industrialização brasileira; d) a questão agrária e o agronegócio; e) os limites da reforma agrária na contemporaneidade; f) considerações finais.

Palavras-chave: Questão agrária. Reforma Agrária. Brasil.

\begin{abstract}
This paper aims at reconstructing the history of the land (agrarian) issue considering the greatest concentration of wealth and resources in the capitalist system. The standpoint is that the growing inequality of the Brazilian model is related to the agrarian issue. Secondly, we analyze the limits currently placed on any possibility of a comprehensive and structural agrarian reform, due to the advancement of the agribusiness over the last ten years, the political demobilization of a significant portion of society that put this issue aside, and the limits of the Brazilian economy in the context of the financial globalization. The paper is divided into six parts: a) colonization and origins of the large landed estates; b) the agro-export model and the incomplete rupture; c) the agrarian issue and the Brazilian industrialization; d) the agrarian issue and the agribusiness; e) the limits of the agrarian reform in the contemporary time; f) final considerations.
\end{abstract}

Keywords: Agrarian Issue. Agrarian Reform. Brazil.

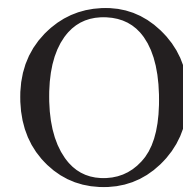

Brasil talvez seja o único "grande" país que vivenciou um profundo e complexo processo de crescimento e desenvolvimento econômico sem promover substanciais mudanças na questão da propriedade fundiária. Desde a colonização portuguesa, passando pela Lei de Terras de 1850 e por todo o processo de industrialização vivenciado no século $\mathrm{XX}$ e ainda em curso, a questão agrária permaneceu quase que inalterada, a despeito de avanços decorrentes das crescentes contradições sociais e econômicas e da correlata violência verificadas no campo. A Europa Ocidental e países como os Estados Unidos (Homestead Act de 1862), China (o Grande Salto para Frente, de 1959) e URSS (a partir da Revolução de 1917) em algum momento, e de diferentes formas, promoveram o maciço acesso da população à terra, e mesmo vizinhos latino-americanos, como a Argentina, forjaram sociedades mais abertas no que se refere à propriedade da terra (vide as políticas de colonização do território implementadas no século XIX) do que a brasileira.

Nestes termos, o objetivo deste breve artigo é o de reconstituir a trajetória da questão fundiária (e agrária ${ }^{1}$ ) na experiência de maior concentração de ri-

1. Entendemos a questão agrária nos mesmos termos que a professora Sônia Regina de Mendonça: "o conjunto de inter-relações e contradições derivado de uma estrutura fundiária altamente concentrada que, por 
queza e recursos vivenciada no âmbito do sistema capitalista, partindo-se da premissa de que a crescente desigualdade do modelo brasileiro passa necessariamente pela questão agrária. O texto será dividido em seis sessões: a) colonização e origens do latifúndio; b) o modelo agroexportador e a ruptura incompleta; c) a questão agrária e a industrialização brasileira; d) a questão agrária e o agronegócio; e) os limites da reforma agrária na contemporaneidade; f) considerações finais.

\section{Colonização e origens do latifúndio (1500-1822)}

Nos quadros do Antigo Regime a América Portuguesa emergiu como destacada área da colonização moderna, o que, desde logo, estabeleceu determinado padrão de ocupação do solo. A partir de legislação já existente em Portugal e aplicada anteriormente em Cabo Verde e na Ilha da Madeira, optou-se pela divisão do território em extensas capitanias de caráter hereditário. Na verdade a Coroa portuguesa detinha a posse da terra, cedendo-se aos ocupantes a concessão de uso com direito a herança, de modo que inexistia a propriedade privada da terra nesse modelo adotado inicialmente, apenas a sua concessão. A ocupação corresponde ao papel dessa região na típica divisão internacional do trabalho da época moderna, na qual coube às colônias americanas a produção de gêneros agrícolas complementares com vistas à acumulação mercantil nas metrópoles europeias. Após um breve interstício extrativista ocorrido na primeira metade do século XVI, ao qual correspondeu uma ocupação irregular e superficial do território, a produção de açúcar ganhou destaque, e o modelo de plantation assumiu preeminência, sobretudo na região Nordeste do futuro Brasil.

Caracteriza esse modelo a recorrência das grandes unidades produtoras de amplas escalas, um tipo de agricultura altamente especializada, sendo absolutamente subsidiária a produção de outros gêneros e culturas, e a adoção da mão

\footnotetext{
seu turno, também determina a concentração de poder econômico, político e simbólico, criando estruturas de sujeição da população rural e uma cultura incompatível com um tipo de exploração racional da terra [...]. Em outros termos, é possível afirmar que o desenvolvimento do país está entravado por uma 'questão agrária' quando a tessitura das relações econômicas, sociais, políticas e culturais, no meio rural, produz uma dinâmica perversa que bloqueia tanto o esforço para aumentar a produção e a produtividade no campo, quanto as tentativas de melhorar o nível de vida da população rural, e, sobretudo, seu grau de participação no processo político democrático" (2006, p. 78).
} 
de obra escrava africana, oriunda, notadamente da região da atual Angola, África. Evidentemente, como nos ensina Fernando Novais (2001), o sentido da extraterritorialidade da oferta de mão de obra, que perdurará até a abolição da escravidão em 1888, é dado pela própria realização do capital mercantil naquele que constituiu o negócio mais rentável de toda a época moderna: o tráfico de cativos. Latifúndio - monocultura e escravidão, eis a deletéria herança de nosso passado colonial.

Outra característica marcante da exploração colonial é o seu caráter contraditoriamente cíclico e contínuo. Referimo-nos aqui, por um lado, à recorrência de ciclos exploratórios muito bem demarcados, apontados primeiramente por Roberto Simonsen (1957) e difundidos por Celso Furtado em Formação econômica do Brasil, uma das mais influentes obras da literatura econômica brasileira. São eles: o ciclo extrativista do pau-brasil, o ciclo da cana de açúcar, o ciclo do ouro e o ciclo do café. Por outro lado, apesar da alternância secular de produtos agrícolas e minerais predominantes, cabe ressaltar o caráter de continuidade de nossa formação econômica. Vejamos, por exemplo, o caso do açúcar. Apesar da recorrente queda de preços verificada no mercado açucareiro nos séculos XVII e XVIII, em função da concorrência com o açúcar das Antilhas Holandesas, a estrutura produtiva dos engenhos de açúcar possuía perenidade, não se dissolvia perante a continuada queda dos lucros, como poderíamos esperar de uma empresa moderna. Em momentos de alta dos preços, nos quais o mercado externo absorvia quantidades crescentes de açúcar, o engenho adquiria maquinário (incipientes instrumentos e caldeiras), escravos (sempre que a oferta fosse elástica) e expandia a fronteira agrícola, sempre em constante movimento dada a relativa abundância de terras, de modo que essas unidades auferiam lucros significativos sem alterar a estrutura produtiva, que crescia extensivamente. Em momentos de baixa dos preços, os retrocessos tampouco acarretavam qualquer modificação estrutural; mesmo que a unidade produtiva chegasse a paralisar-se, o "empresário" não incorria em grandes perdas, uma vez que os gastos de manutenção (custos) dependiam principalmente da própria utilização da força de trabalho escrava já capitalizada, e grande parte do gasto de consumo estava assegurada pela utilização dessa força de trabalho, de modo que os escravos eram reconvertidos para outras funções, tais como o plantio de fumo, mandioca e demais produtos comercializados internamente ou destinados à subsistência. Apesar de uma menor taxa de retorno no comércio internacional, os senhores de engenhos e os grandes 
proprietários não pulverizavam sua riqueza composta basicamente por terras e escravos e assim mantinham a base de seu poder e a recorrência do latifúndio na história brasileira. Como afirmou Furtado (2007, p. 89): “o crescimento da empresa tendia a ser puramente em extensão, isto é, sem modificações estruturais, e as paralisações ou retrocessos nesse crescimento não tendiam a criar tensões capazes de modificar a estrutura; crescimento significava ocupação de novas terras e aumento das importações, decadência vinha a ser redução de gastos em bens importados e na reposição da força de trabalho (também importada), com diminuição progressiva, mas lenta, no ativo da empresa, que assim minguava sem se transformar estruturalmente". Não havia, assim, nenhuma possibilidade de que o crescimento com base no impulso externo originasse um processo de desenvolvimento de autopropulsão e de superação do latifúndio, de modo que essa realidade vigorou por pelo menos quatro séculos da história brasileira.

Há que se salientar também que, dada a condição de baixa integração do território e de isolamento dos mercados, mesmo os pequenos produtores independentes viviam em função das grandes unidades, prestando serviços subsidiários e repassando a sua produção de cana de açúcar e de produtos alimentícios, numa "lógica do favor" e de dependência que impediu, no Brasil, a formação de um campesinato que pudesse se configurar como força política revolucionária, tal como no caso francês. A experiência do latifúndio canavieiro e dos engenhos de açúcar no Nordeste brasileiro fora a experiência de maior fixação e ocupação do território em todo o período colonial latino-americano, daí a sua relevância como padrão de ocupação do solo na região.

\section{0 modelo agroexportador e a ruptura incompleta (1822-1930)}

Conforme assinalou Florestan Fernandes (2006), o processo de superação do estatuto colonial, ocorrido no bojo da queda do Antigo Regime, apresentou um caráter dual. Se, por um lado, os processos de independência dos países latino-americanos podem ser caracterizados como revolucionários, uma vez que internalizaram os centros de decisão e criaram um espaço político que representasse os interesses das respectivas elites nacionais, por outro lado não romperam com o modelo agroexportador inserido em determinada divisão internacional do trabalho capitaneada pela Inglaterra. $\mathrm{O}$ fato é que essas economias 
permaneceram reflexas e dependentes dos impulsos advindos do mercado internacional e os fluxos de renda eram para lá direcionados nos quadros de um imperialismo informal. Entendendo o século XIX como o momento de definição da hierarquia entre as nações, coube ao Brasil marcar passo numa posição absolutamente subordinada no que se refere à industrialização (avanço das forças produtivas) e aos fluxos de capitais.

As formações econômicas latino-americanas, e em especial o Brasil, continuaram, apesar da independência, mantendo sua heterogeneidade estrutural-verdadeiras economias de enclave pouco atreladas ao conjunto do território, e parcela significativa da população pouco se integrava à dinâmica promovida pelo mercado externo e interno, de modo que a questão fundiária quase nada se alterou. A continuidade da escravidão no tempo (só foi abolida em 1888) e no espaço (abarcava todo o espaço agora nacional) corroborou tal característica e impediu a formação de uma estrutura social que demandasse amplo acesso à terra. Nesses termos, inexistia, no tecido social, um grupo composto por uma classe média ou mesmo um protoproletariado rural que poderia constituir demanda para um mercado de terras.

Assim, não se verificavam contestações populares de caráter universal (tal como nas revoluções burguesas clássicas) que poderiam pressionar por alterações na questão fundiária brasileira, principalmente porque o processo de independência contornou o problema da abolição da escravidão. Dado o caráter elitista e intradinástico das demandas colocadas naquele momento, o conjunto da população pouco participou do processo, e o Brasil perdeu uma oportunidade histórica de desenhar outro tipo de desenvolvimento capitalista: a escravidão se perpetuaria até o final do século XIX, sendo o país, ao lado de Cuba, os últimos do continente a abolir a escravidão.

As primeiras tentativas de mudança na questão da terra só vieram à tona em 1850, com a chamada Lei de Terras (Silva, 2008). Tal iniciativa foi motivada pela crise da escravidão patrocinada de fora para dentro, dada a pressão exercida pela Inglaterra sobre o tráfico negreiro, não derivando a questão agrária, assim, de uma luta interna relacionada ao acesso à terra e à propriedade. ${ }^{2}$ No âmbito da crise do mercado internacional de cativos, e já vislum-

2. "Para o senhoriato rural, não se colocava [como nunca se colocou] com premência a questão da regularização da propriedade da terra enquanto o antigo sistema produtivo colonial — baseado no trabalho 
brando a superação dessa forma de organização da produção, o governo brasileiro promoveu as primeiras alterações na legislação fundiária, lembrando que ainda vigoravam as ordenações filipinas e o regime de sesmarias (cessão) herdado de Portugal. A lei de 1850 representou a introdução do sistema de propriedade privada das terras, estabelecendo, desde então, um mercado de terras. ${ }^{3}$ As terras que não se reduziam à condição de propriedade de algum ocupante foram declaradas devolutas, pertencentes ao Estado brasileiro, que fora, evidentemente, conivente com fraudes, títulos e documentos falsificados e alterações topográficas, de modo que a lei pouco alterou a conformação fundiária nacional e muito menos a correlação de forças políticas no seio do Império. Na verdade, o objetivo dessa legislação era bloquear o acesso à terra por parte da população supostamente livre (dado o esgotamento da escravidão), antecipando o que poderia ser uma ameaça ao poder de parcela da elite nacional, qual seja, a quebra do monopólio da terra. Nestes termos, e ainda com Florestan Fernandes, bloqueia-se a constituição de uma ordem social competitiva e bloqueia-se violentamente o processo de mobilidade social, como que congelando o tempo histórico e político, e, nesse bojo, a questão agrária.

Retornando à questão dos ciclos exploratórios, salientamos que a partir de 1830 o Brasil perpetuou sua inserção agroexportadora no sistema capitalista internacional com a produção de café, agora nucleada na região Sudeste do país (Rio de Janeiro, Espírito Santo, Minas Gerais e, principalmente, São Paulo). Apoiado ao mesmo tempo na sua imensa fronteira agrícola e na expansão do mercado mundial, o café tornou-se rapidamente uma mercadoria de grande valor no comércio internacional, o que atraiu o capital mercantil (inglês) que encontrou nessa região uma fronteira tardia de expansão, depois de suas aventuras imperialistas na Ásia e na África (Tavares, 1999, p. 458). Tratava-se, na verdade, da incorporação do espaço econômico brasileiro via financiamento de ferrovias, serviços de utilidade pública e de indústrias ligadas ao beneficiamen-

\footnotetext{
escravo e na apropriação livre das terras — pudesse manter-se. O desenvolvimento da economia cafeeira que começava a alterar a feição do país, em muitos aspectos, não modificou este quadro [...] os ajustamentos e compromissos que sustentavam essa situação protelavam a adoção de medidas modernizadoras que adaptassem a sociedade aos novos tempos, em que o capitalismo começava a dominar em escala internacional" (Silva, 2008, p. 127).

3. "Art. $1^{\circ}$ Ficam proibidas as aquisições de terras devolutas por outro título que não seja o de compra [...]”. Cf. Lei de Terras de 1850 (Stédile, 2005, p. 283).
} 
to do café. Nesses termos, a economia brasileira se tornou mais complexa, ${ }^{4}$ aumentando o seu grau de diversificação e de urbanização ao mesmo tempo em que a questão escravocrata era superada. As pressões externas (Inglaterra) e as internas (orientadas pelo próprio avanço da acumulação capitalista) superaram o anacronismo dessa forma de produção pré-capitalista, surgindo daí a necessidade de utilização de outro tipo de mão de obra. Necessitando de "braços para a lavoura", os governos provinciais, e, posteriormente estaduais, colocaram em prática políticas de subsídio à imigração de europeus, notadamente italianos. Diferentemente de outros modelos de colonização surgidos na segunda metade do século XIX, tais como o australiano e o norte-americano, o governo brasileiro, apesar de algumas parcas experiências no Sul do país, não possuía um projeto de ocupação da terra baseado na pequena propriedade e na criação de um campesinato. O que estava em questão era o abastecimento de mão de obra para as grandes unidades produtoras de café e a viabilização do avanço e da ocupação da fronteira agrícola. Nestes termos, grande parte do fluxo de imigrantes advindos em finais do século XIX, ao chegar ao Brasil, foi direcionada às fazendas e se submeteu a relações de trabalho que, se por um lado podem ser qualificadas juridicamente pela liberdade (um contrato entre duas partes livres e iguais), por outro impôs a essa população relações de trabalho absolutamente deletérias, tais como as parcerias e o colonato ${ }^{5}$ (Faleiros, 2010).

Por certo, alguma mobilidade social se verificou naquele contexto, uma vez que alguns colonos, principalmente aqueles com maiores famílias, e que contaram com um momento favorável dos preços do café ou contratos mais

4. Interessante notar que o complexo econômico cafeeiro (referindo-se a São Paulo) se diferencia das demais formações regionais brasileiras em função do assalariamento, ou em relações que tendiam para isso, sendo o fundamento qualitativamente diferenciado. Segundo Wilson Cano não se verificou no restante do país uma articulação entre os componentes do complexo econômico que redundasse nos seguintes desdobramentos: a) a atividade produtora de café (atividade nuclear), b) agricultura produtora de alimentos e matérias-primas, c) a atividade industrial (equipamentos de beneficiamento do café, indústria de sacarias, bens de consumo não duráveis, notadamente têxteis, d) a implantação e desenvolvimento do sistema ferroviário, e) a expansão do sistema bancário, f) a atividade do comércio de importação e exportação, g) desenvolvimento de infraestrutura: portos, armazéns, transportes urbanos e comunicações, h) urbanização, i) a atividade do estado pela ótica do gasto público (Cano, 1998, p. 25).

5. O colonato pode ser definido como uma combinação única de salários monetários fixos por cada cova de café formada, um salário em espécie advindo do acesso à terra para o cultivo de alimentos, e uma remuneração advinda de trabalhos volantes na colheita de café. A posse da terra é fundamental aos fazendeiros nesse sistema, uma vez que permite operar substancial redução nos salários monetários dos colonos. 
favoráveis, conseguiram superar a condição de assalariamento (monetário ou em espécie) e se tornaram proprietários (ou posseiros) de pequenas glebas situadas nas franjas das maiores unidades produtoras, fenômeno que se verificou de forma mais intensa no estado de São Paulo. Porém, mesmo nessa experiência, a centralidade do latifúndio mostrava-se irrefutável, apesar da expansão de uma agricultura de alimentos e da diversificação crescente da produção voltada para o mercado interno. O fato é que a precária conjuntura mercantil não reunia forças para promover alterações mais substanciais na estrutura social brasileira como de resto contrariar uma história marcada por quatro séculos de latifúndio (Guimarães, 1968), e mesmo os avanços urbano-industriais circunscreviam-se ao caráter agroexportador dessa formação econômica. Entenda-se que não estamos aqui negando a existência de pequenos produtores no Brasil, apenas assinalando que ocupavam posição subsidiária do ponto de vista da inserção internacional, da acumulação de capitais e das políticas governamentais, que, neste modelo, sempre privilegiaram as grandes unidades produtoras. A criação de um complexo econômico baseado na exportação de café na região Sudeste do Brasil recrudesceu tal forma de inserção, que só foi parcialmente superada com o profundo choque adverso da crise de 1929 e da revolução de 1930.

\section{A questão agrária e a industrialização brasileira}

O processo de industrialização da economia brasileira adquiriu uma natureza completamente diferente a partir de 1930. Se no passado a indústria ligava-se mais diretamente à produção de bens salários e à de bens de capital destinados à produção, beneficiamento e transporte de café, sendo, portanto, reflexa da demanda internacional, em diante desse momento orientou-se endogenamente, buscando efeitos dinamizadores a partir de dentro. No período compreendido entre 1933 e 1955 adentra-se na fase da industrialização restringida, uma vez que a capacidade de importar permanecia reduzida em função das guerras e dos baixos preços das exportações nacionais. Convivendo com crescentes problemas nas contas nacionais, o Brasil iniciou o aprofundamento de seu esforço industrialista a partir da sobreutilização da capacidade instalada, da ampliação da jornada de trabalho e da substituição de importações. Evidentemente, a manutenção de tal esforço passava pela produção voltada para a exportação, e o governo se empenhou na criação de mecanismos de manutenção da renda in- 
terna que demandavam algum tipo de política de valorização e defesa do preço do café, o que foi empreendido até 1937.

Entretanto, a mudança de eixo dinâmico exigiu um esforço do Estado na medida em que significava uma ruptura com o caminho natural dessa formação econômica. De saída, como destaca Francisco de Oliveira (2003, p. 40), foi necessário fazer da indústria capitalista industrial a unidade mais rentável do conjunto da economia, o que significou drástica redução e controle sobre os salários urbanos e sobre os preços dos produtos agrícolas, deprimindo-os, o que, ao lado de taxas de juros mais elevadas para o campo, solapou a centralidade da produção agrícola na economia brasileira da época do ponto de vista das taxas de retorno. Nesses termos, percebe-se um intenso mecanismo de transferência de capitais das atividades agrícolas para as industriais, uma vez que, financiadas com juros reais negativos e altamente lucrativas pelo lado dos salários, ${ }^{6}$ verificando-se o correlato fluxo de renda campo-cidade e um dos processos de migração mais violentos do século XX, sendo esta a origem dos graves problemas urbanos hoje verificados nas grandes cidades brasileiras. Migrantes advindos das regiões Norte, Nordeste e Centro-Oeste promoveram verdadeiras explosões demográficas no Rio de Janeiro, em São Paulo e demais capitais do Centro-Sul do país, constituindo mão de obra excedente que, ao lado da legislação trabalhista vigente, pressionou de forma negativa os salários solapando qualquer possibilidade de uma relação capital/trabalho minimamente aceitável.

A agricultura, bem como o latifúndio, adquire outro papel nessa situação. É claro que continua sendo fundamental nessa economia, uma vez que é responsável pelas entradas de divisas destinadas ao suprimento das necessidades de bens de capitais e intermediários de produção externa e também pelo abastecimento do mercado interno de alimentos e de matérias-primas estratégicas, como o algodão. Porém a atividade agrícola perde a centralidade do ponto de vista da dinâmica econômica agora capitaneada pela indústria e pela renda in-

6. "O decisivo é que as leis trabalhistas fazem parte de um conjunto de medidas destinadas a instaurar um novo modelo de acumulação. Para tanto, a população em geral, e especificamente a população que afluía às cidades, necessitava ser transformada em exército de reserva. Essa conversão de enormes contingentes populacionais em exército de reserva, adequada à reprodução do capital, era pertinente e necessária do ponto de vista do modo de acumulação que se iniciava ou que se buscava reforçar, por duas razões principais: de um lado, propiciava o horizonte médio para o cálculo econômico empresarial, liberto do pesadelo de um mercado de concorrência perfeita, no qual ele devesse competir pelo uso dos fatores; de outro, a legislação igualava reduzindo, antes que incrementando, o preço da força de trabalho" (Oliveira, 2003, p. 38). 
terna. Neste ponto é necessário ter em conta o processo de transferência e ampliação da renda na e para a indústria, via rebaixamento dos salários (o que passava pela legislação e pelo estabelecimento de um robusto mercado interno de gêneros alimentícios), pelo diferencial de taxas de juros para empréstimo e capitalização entre os diferentes setores da economia, e pelos controles diretos dos preços agrícolas exercidos por órgãos públicos de regulação chamados "institutos", tais como o IBC - Instituto Brasileiro do Café e o IAA, Instituto do Açúcar e do Álcool, criados a partir de 1933 com vistas ao estabelecimento de deseconomias nesses setores.

Seria de se esperar que com a modernização da economia brasileira o campo sofresse alterações significativas do ponto de vista da composição técnica do capital, porém é justamente neste quesito que economias com passado colonial, marcadas pela heterogeneidade estrutural, revelam suas limitações no que se refere ao desenvolvimento econômico. Nessa condição de subdesenvolvimento, gestada historicamente, a acumulação primitiva não se dá apenas na gênese do capitalismo. Essa fase é estrutural, e não apenas genética como demonstrou Oliveira (2003, p. 41), o que, no caso brasileiro, significa dizer que as atividades agrícolas, dada as elásticas ofertas de mão de obra e de terras (fronteira agrícola), continuaram reproduzindo-se a partir de relações de superexploração da força de trabalho que podem ser qualificadas como pré-capitalistas. ${ }^{7}$ A resposta dos latifúndios à depressão de sua lucratividade a partir do choque adverso de 1930 foi dada não a partir de impulsos com vistas à ampliação da produtividade, como seria de se esperar que ocorresse em economias desenvolvidas poupadoras de mão de obra, mas, pelo contrário, justamente a partir do recrudescimento de formas pretéritas de organização e exploração do trabalho. Uma das formas clássicas de exploração da mão de obra passava pela posse ou propriedade da terra, na qual os latifundiários forneciam um acesso parcial e transitório aos seus subordinados, que se viam na obrigação de dali extraírem os seus salários em espécie, o que mantinha o custo-salário favorável em relação à intensificação do capital, perpetuando, novamente no tempo e no espaço, determinado tipo de atividade agrícola com baixíssima relação capital/

7. Salientamos aqui o fato de que o Brasil, até os dias atuais, convive com a realidade do trabalho escravo, sobretudo nos estados do Pará, Mato Grosso, e mesmo na metrópole de São Paulo, com as denúncias de exploração escrava da mão de obra boliviana. Para além da escravidão, podemos citar as formas de exploração calcadas na parceria, colonato e no trabalho do boia-fria. 
trabalho, com salários subumanos e ocupação superficial e depredatória da terra, referindo-se a técnicas de cultivo absolutamente anacrônicas e ultrapassadas. Trata-se do polo atrasado das economias subdesenvolvidas. ${ }^{8}$

De outro lado, convivendo com o atraso, temos a industrialização que, mesmo truncada, uma vez que não foram endogeneizadas a capacidade de inovação tecnológica e a capacidade de autofinanciamento, respondia pela face moderna da economia brasileira. Nos enclaves industriais do Centro-Sul verificavam-se intensas transformações estruturais, tais como a urbanização, a generalização de relações de assalariamento, significativo aumento do produto, intensa mobilidade social, já que os salários, mesmo deprimidos, eram superiores aos ganhos no campo, intensa migração interna, como já vimos, mudanças profundas nos padrões de moradia e consumo e mesmo no formato das famílias. Tem-se a impressão, ao se observar o Brasil de então, que vários tempos históricos convivem simultaneamente.

Essa nova realidade aparentemente ambígua e contraditória indica uma "unidade de contrários" nos termos de Oliveira (2003). Com o avanço da industrialização, a demanda por bens salários ampliou-se consideravelmente, e a resposta da agricultura foi dada pela incorporação de novas terras, das fronteiras internas de um território continental. Ao crescer extensivamente as pressões pela modernização permaneciam contidas, e a sociedade que avançou pelos sertões do Pará, Mato Grosso, Goiás, Paraná, como de resto em todos os estados de colonização recente, reproduzia um padrão já conhecido: o trabalhador rural ou morador ocupa a terra, desmata predatoriamente, destoca, cultiva as lavouras temporárias chamadas "de subsistência" e depois prepara as lavouras permanentes ou as pastagens que não são deles, mas dos proprietários, num tipo de exploração do trabalho que não passava necessariamente pela separação dos produtores dos meios de produção. ${ }^{9}$ Ficava-se a meio passo do campesinato e do assalariamento, num modelo de reprodução da miséria que cumpria o seu papel: abastecer os centros modernos com bens salários de baixo custo. É sintomático,

8. Florestan Fernandes (2008, p. 61) explica nos seguintes termos a persistência de formas arcaicas na sociedade brasileira: "Sob o capitalismo dependente, a persistência de formas arcaicas não é uma função secundária e suplementar. A exploração dessas formas, e sua combinação com outras, mais ou menos modernas e até ultramodernas, fazem parte do "cálculo capitalista' do agente econômico privilegiado".

9. Desta característica derivam algumas interpretações que reclamavam a existência de formas de exploração tipicamente feudais na realidade brasileira no âmbito do Partido Comunista Brasileiro, tais como Alberto Passos Guimarães e Nelson Werneck Sodré. 
segundo Oliveira, o fato de que a maioria dos gêneros alimentícios vegetais (arroz, feijão, milho) que abasteciam os grandes mercados foi produzida em zonas de ocupação recente, sendo que a permanente baixa cotação desses alimentos contribuiu decisivamente para o processo de acumulação nas cidades.

Esses dois fenômenos, quais sejam, a recorrência de relações heterocrônicas no campo e o baixo preço dos bens que compunham a cesta de consumo dos trabalhadores urbanos formam, no fundo, uma unidade que contribuiu para a viabilidade de um modelo de capitalismo baseado em lucros extraordinários no setor dinâmico dessa formação econômica. Nestes termos, mesmo em regiões mais integradas, observa-se um paradoxo, no qual uma agricultura primitiva é capaz de concorrer com uma agricultura moderna incorporadora de insumos, adubos, fungicidas, pesticidas, novas técnicas de cultivo e, sobretudo, mecanização. Nas palavras de Francisco de Oliveira (2003, p. 45):

o modelo é viabilizado pela manutenção de baixíssimos padrões do custo da reprodução da força de trabalho ${ }^{10} \mathrm{e}$, portanto, do nível de vida da massa trabalhadora rural, essa é a natureza da conciliação existente entre o crescimento industrial e o crescimento agrícola: se é verdade que a criação do novo mercado urbano-industrial exigiu um tratamento discriminatório e até confiscatório sobre a agricultura, de outro lado é também verdade que isso foi compensando até certo ponto pelo fato de que esse crescimento industrial permitiu às atividades agropecuárias manterem seu padrão primitivo, baseado numa alta taxa de exploração da força de trabalho".

A agricultura, nesse modelo, cumpre papel vital para a expansão do sistema, seja fornecendo os alimentos no esquema já descrito, seja fornecendo os contingentes de força de trabalho, compatibilizando o processo global de acumulação da economia. Evidentemente, o nexo entre esses dois mundos é dado pelo latifúndio, nas zonas antigas e nas fronteiras de expansão, e justamente por isso a legislação trabalhista não obteve nenhum tipo de aplicação no campo no perío-

10. Isto indica um modelo de industrialização que, pelo lado da demanda, será cada vez mais dependente do consumo conspícuo das elites e das classes médias urbanas, uma vez que os trabalhadores rurais e mesmo os proletários urbanos de menor qualificação/remuneração não constituirão mercado para os bens industrializados, principalmente quando o modelo avançava, a partir de 1956, para a produção de bens de consumo duráveis. Assim, os desnivelamentos sociais do ponto de vista do padrão de consumo serão gritantes nessa economia. 
do em tela, e a questão agrária como a correlação de forças políticas pouco avançou. Maria da Conceição Tavares (1999, p. 455) assim sintetiza a questão:

A fuga para frente do dinheiro e das normas só foi possível porque houve a fuga para frente de populações em busca de espaço livre, que ao ser ocupado reproduzia, na fronteira de expansão da acumulação capitalista, as relações sociais e econômicas desiguais e combinadas que constituem a marca mais forte da heterogeneidade social crescente da sociedade brasileira. [...] As formas de ocupação do território sempre confirmaram a tendência à concentração crescente da renda e da riqueza e à exploração brutal da mão de obra.

O fato de aqui indicarmos uma correlação de força desfavorável aos trabalhadores rurais nas questões que envolviam a posse da terra não significa que não tenham existido lutas e iniciativas de associação na história no campo brasileiro. Muito pelo contrário, indicam a grande dimensão do desafio das classes trabalhadoras num cenário de "circuito fechado". A pesquisa de Welch (2010) reconstitui cuidadosamente as raízes do movimento sindical camponês no Brasil, especificamente em São Paulo, indicando que precocemente a luta no campo se fez presente na realidade brasileira, tendo, como exemplo, a greve ocorrida nas fazendas de café de Ribeirão Preto (SP), em 1912, na maior região produtora de café do mundo. A partir da vinculação de sindicatos rurais, de parte da Igreja Católica e do PCB — Partido Comunista Brasileiro —, o autor percebeu o avanço da mobilização e das teses acerca da questão agrária e das formas de politização e luta dos trabalhadores rurais.

\section{A questão agrária e 0 agronegócio}

A partir das reformas econômicas empreendidas no âmbito do PAEG (Plano de Ação Econômica do Governo, de 1964) e do posterior "milagre econômico", período compreendido entre 1967 e 1973, no qual a economia brasileira cresceu consideravelmente, o modelo brasileiro revelou-se na sua plenitude conservadora. Uma das vias empreendidas com vistas à ampliação da acumulação de capitais foi o arrocho salarial promovido a partir desse momento. Em 1960, o salário mínimo perfazia 100,30 (sendo o índice igual a cem em julho de 1940), reduzindo-se para 54,48 em 1974. Nesse mesmo período a ração essencial consumia 33,96\% do salário mínimo em 1960 e 68,14\% em 1974. O 
PIB per capita (igual a cem em 1940) evoluiu do índice 195,19 em 1964 para o índice 370,19 em 1974 (Costa, 1997, p. 57). Esses dados evidenciam a violência do arrocho salarial e o aumento considerável dos itens básicos à sobrevivência, bem como o avanço do produto, certamente com menor participação relativa dos salários.

Por essa via, a questão agrária foi tensionada, uma vez que o governo militar patrocinou iniciativas que promoveram uma concentração fundiária em escalas até então não verificadas nas zonas de expansão da fronteira agrícola sediadas na região amazônica, tais como o Projeto Jari, idealizado pelo norte-americano Daniel Ludwig na divisa dos estados do Pará e do Amapá, com vistas à produção de celulose, cujas propriedades somavam 3,6 milhões de hectares, uma área superior a países como a Holanda e o Líbano (Martins, 1982, p. 139). Os latifúndios no Nordeste pareciam minifúndios perto das fazendas amazônicas. Uma área como essa, num cálculo grosseiro, poderia dar emprego a 1 milhão de famílias, cerca de 5 milhões de pessoas (Idem). Evidentemente, a grande propriedade no Brasil tradicionalmente não tem interesse na produção de alimentos para o mercado interno, optando pela exportação de uma produção especializada protegida por amplos subsídios e benefícios fomentados por um governo ávido por entrada de divisas, o que distorcia ainda mais a realidade da propriedade da terra no Brasil: em 1975, ao fim do "milagre", as grandes fazendas, acima de 3 mil hectares, tinham apenas 3\% de sua área destinada às lavouras de alimentos (Martins, 1982, p. 40). Caracterizando ainda melhor essa realidade, nesse mesmo ano $52 \%$ dos estabelecimentos rurais possuíam menos de dez hectares e abrangiam apenas $2,8 \%$ da área total.

$\mathrm{O}$ fato é que o grande salto para a frente empreendido pelos militares pressupunha uma aceleração da industrialização — a dita modernização — sem reformas estruturais de amplo alcance e sem um processo de mobilidade social mais amplo, uma vez que o grande objetivo das elites nacionais era avançar a acumulação capitalista sem abrir mão do controle sobre a mudança social, ou, em outros termos, o objetivo (alcançado por sinal) era "congelar" a luta de classes, o tempo histórico, evidenciando uma resistência sociopática à mudança (Fernandes, 2008, p. 185). Assim, a dolorosa modernização verificada na agricultura nos anos de 1960 e 1970 teve como uma de suas precondições a derrota de qualquer proposta de uma efetiva reforma agrária, optando-se por um desenvolvimento capitalista no campo com a manutenção de uma estrutura fundiária pretérita. Isso, evidentemente, excluía parcela significativa da popu- 
lação brasileira das "benesses" dos ganhos de produtividade e acentuaria as pressões inflacionárias contidas no modelo, como de resto expulsaria as pessoas do campo numa escala ainda mais avassaladora.

Coetaneamente ao "milagre econômico", a mancha dos latifúndios se expandiu para a Amazônia e todo o Norte do Brasil - promovendo impacto ambiental incalculável —, como também se viu revigorado em áreas até então dominadas pela pequena agricultura, como no interior de São Paulo e no norte do Paraná. O agronegócio, o complexo industrial voltado para a agricultura, se impôs como realidade dominante, ampliando a tenebrosa articulação entre expropriação e exploração dos trabalhadores rurais. Delgado (2005, p. 53-54) assim sintetiza a questão:

Em certo sentido pode-se visualizar nesse processo de modernização um pacto agrário tecnicamente modernizante e socialmente conservador, que, em simultâneo à integração técnica da indústria com a agricultura, trouxe ainda para o seu abrigo as oligarquias rurais ligadas à grande propriedade territorial [...]. No período da "modernização conservadora" estas oligarquias serão novamente assimiladas em programas e projetos especiais, os quais garantem ao latifúndio a obtenção de inúmeras linhas de apoio e defesa na nova estrutura de defesa fiscal e financeira do setor rural. A valorização extraordinária dos patrimônios territoriais, muito além do crescimento real da economia, é um sinal conservador desse projeto de modernização.

Nos anos 1980, em função do esgotamento do modelo brasileiro e da correlata crise da dívida, impõe-se a necessidade premente de geração de saldos comerciais crescentes, gerados, evidentemente, pela grande agricultura. A área colhida de cana-de-açúcar se ampliou de 2.607.628 para 4.272.602 hectares entre 1980 e 1990, a área destinada à soja se ampliou de 8.774 .023 em 1980 para 11.487.303 em 1990, e o número de bovinos abatidos passou de 9.572 .534 para 13.374.663 no mesmo período. Há que se considerar no período o esforço governamental no âmbito do projeto Proálcool, visando reduzir as exportações de petróleo e os constrangimentos no balanço de pagamentos, que teve como consequência uma ampliação da produção de metros cúbicos deste combustível de 1.388 .000 em 1977 para 12.340 .000 em $1987 .{ }^{11}$ O resultado foi uma reversão

11. Disponível em: <www.ipeadata.gov.br>. Acesso em: 28 ago. 2011. 
drástica no saldo comercial brasileiro, partindo-se de um saldo negativo de 3,5 bilhões de dólares em 1980 para um saldo positivo de aproximadamente 14,5 bilhões de dólares em 1992. Esses saldos, durante a década de 1980, foram destinados ao pagamento e rolagem do endividamento externo, estratégia que englobava não só a expansão do latifúndio e da produção especializada voltada para a exportação, mas uma restrição violenta nas importações, num típico ajuste recessivo-periférico. Evidentemente, o ajuste do modelo passou pelo recrudescimento da maldição brasileira: a vocação agrícola.

Dos anos 1990 aos dias atuais, o setor agrícola obteve expressivo ganho de produtividade, certamente em função de expressivo ganho de produtividade. Como salienta Jezus (2010, p. 342), a produção agrícola tem aumentado significativamente, o que demonstra uma acomodação da velha estrutura fundiária aos interesses da grande indústria e a típica capacidade brasileira de crescer economicamente sem realizar reformas. Entre 1996 e 2005 os saldos advindos das atividades agropecuárias saltaram de 7,9 para 28,6 bilhões de dólares, alcançado 63 bilhões de dólares em 2010 (dados do Ipea).

Aárea destinada ao cultivo da soja se ampliou de 11.487.303 para 23.290.696 hectares entre 1990 e 2010, a de cana-de-açúcar, de 4.272.602 para 9.146.615 no mesmo período. O número de cabeças de gado abatidas, entre 1990 e 2009 , elevou-se de 13.374.663 para 27.974.982, e o de aves abatidas nesse mesmo período passou de 962.029.422 para 4.776.233.239 interessante notar que nas lavouras voltadas mais diretamente ao mercado interno, tais como milho, arroz, feijão e trigo, a área de cultivo pouco se ampliou, apesar do destacado aumento de produtividade, indicando que a incorporação de novas terras - o avanço da fronteira agrícola - e mesmo a reconversão de áreas mais antigas, ocorreu no sentido de uma especialização na produção de gêneros agrícolas com preços crescentes no mercado internacional (inflação de commodities), dos quais a soja merece destaque. Nestes termos, o país tem caminhado para a "primarização" de sua economia, regredindo historicamente nos quadros de uma reversão neocolonial. A participação das commodities primárias ${ }^{12}$ na pauta de exportações brasileiras subiu de $37 \%$ para $51 \%$ entre 2000 e 2010 , assim como a participação do país no comércio mundial de bens se elevou de 0,88\% em 2000 para $1,26 \%$ em 2009. No âmbito do grupo commodities, a participação relativa subiu

12. Inclui agricultura, pecuária e mineração, em especial o minério de ferro. 
de $2,77 \%$ para $4,66 \%$ no mesmo período, sendo que a participação desse grupo no comércio mundial total se elevou de $11,6 \%$ para $13 \%$, lembrando que essa rubrica, segundo metodologia da Unctad, não incorpora as commodities energéticas (De Negri; Alvarenga, 2010). Como demonstram os dados, ainda com os autores, a participação de produtos industrializados de baixa, média e alta intensidade na pauta de exportações brasileiras mostrou-se estável com tendência à queda entre 2000 e 2009.

Evidentemente, a perversidade dessa opção (desse modelo) para além da manutenção do latifúndio, da exclusão social e dos graves impactos ambientais, revela-se na destinação dos magníficos superávits auferidos, que foram utilizados, em grande medida, para a rolagem de juros da dívida interna e externa nos quadros da mundialização financeira.

\section{Os limites da reforma agrária na contemporaneidade}

Partimos de um alerta: a concentração fundiária tem avançado no Brasil nos últimos dez anos. No âmbito da reprimarização de sua economia circunscrito a um quadro presente e futuro de crescimento exponencial da demanda por combustíveis (biodiese $1^{13}$ ), minérios (especialmente o ferro) e alimentos, a fronteira agrícola do agronegócio tem avançado com bastante vigor. Entre 2003 e 2010 a área das grandes propriedades aumentou de 214.843 .865 para 318.904 .739 ha, de $51,3 \%$ para $55,8 \%$ do total, num crescimento de $48,4 \%$ desse perfil de propriedade no período. ${ }^{14}$ Os demais perfis também avançaram

13. A demanda por etanol estimada será de 52,9 bilhões de litros em 2019 somente no Brasil. Neste ano, estima-se também uma produção de 784 milhões de toneladas de cana para etanol e 351 milhões de toneladas para a produção de açúcar. O custo de produção para o etanol de cana-de-açúcar é de US\$ 0,22 por litro, contra US\$ 0,30 dos Estados Unidos (etanol de milho) e US\$ 0,53 da Europa. Cabe salientar também que o etanol de cana-de-açúcar possui um rendimento energético maior, sendo menos poluente do que o etanol de milho, trigo e de beterraba sacarina. Estes fatores, aliados à possibilidade de retirada de subsídios e tarifas protecionistas por parte dos Estados Unidos, indicam que o agronegócio voltado para a produção de biodiesel se ampliará sobremaneira no Brasil.

14. Fonte: evolução da concentração da propriedade da terra no Brasil medida pelos imóveis 2003-2010. Cadastro do Incra (Instituto Nacional de Colonização e Reforma Agrária), classificação segundo dados declarados pelo proprietário. Sobre a grande propriedade, referimo-nos àquelas cuja área é superior a cinco módulos fiscais. O módulo fiscal é uma unidade de medida expressa em hectares, fixada para cada município, considerando os seguintes fatores: tipo de exploração predominante no município; renda obtida 
nesse período em termos de área. Os minifúndios evoluíram de 38,9 milhões de hectares para 46,6 milhões, as pequenas propriedades de 74,1 milhões para 88,7 milhões, e as médias propriedades de 88,1 milhões para 113,8 milhões de hectares. Contudo, em termos percentuais, essas três faixas de propriedade perderam espaço.

A velocidade dessas alterações se explica por um posicionamento da economia brasileira no sentido de uma maior especialização na produção de commodities primárias (a controversa reprimarização). Como vimos anteriormente, entre 2000 e 2009 a participação brasileira nessas exportações aumentou e, por outro lado, a participação do país na exportação de bens com alta intensidade (segundo metodologia da Unctad, 2002), diminuiu de $0,52 \%$ para $0,49 \%$, numa clara perda de market share (De Nigri; Alvarenga, 2010). Em certa medida, essas alterações derivam de uma estratégia de valorização cambial com vistas a ganhos de produtividade nos setores exportadores, mineradores e de produção de petróleo, dada a crescente demanda mundial capitaneada pela China. Por outro lado, evidentemente, e de forma mais profunda, está no horizonte a desindustrialização e uma forma de inserção na economia mundial que reproduz e amplia a existência do latifúndio na sociedade brasileira. Há que se considerar também que por trás da questão da valorização cambial está a dependência em relação ao capital financeiro, que pressiona por uma elevada taxa de juros e por mecanismos de valorização fictícia da riqueza via dívida pública, baseados, evidentemente, na execução de superávits primários constantes e ampliados.

Enfim, o governo e a sociedade brasileira, nos quadros da mundialização financeira, tem feito uma escolha muito clara, na qual não existe espaço para uma reforma na propriedade da terra. Evidentemente, a ideia de reforma agrária suscita várias interpretações, às quais não é o caso de discutirmos aqui. Porém, quando utilizamos este termo nos referimos, grosso modo, a uma política de redistribuição da propriedade fundiária em favor das pequenas e médias propriedades, o que passa, necessariamente, por uma política fiscal mais rígida com os grandes latifúndios, principalmente os improdutivos, por uma política

\footnotetext{
com a exploração predominante; outras explorações existentes no município que, embora não predominantes, sejam significativas em função da renda ou da área utilizada; e conceito de propriedade familiar. Por exemplo, um módulo fiscal em Aracati (CE) corresponde a 45 ha, já em Caucaia-CE corresponde a 15 ha. Segundo o INCRA, a grande propriedade é aquela superior a cinco módulos fiscais, com área média de 2.440 ha.
} 
de incentivos e subsídios, por uma política educacional e pela concessão de crédito de longo prazo a taxas factíveis. Este, definitivamente, não tem sido o caminho adotado. $\mathrm{O}$ governo não quis sequer, por exemplo, alterar os parâmetros referenciais de mensuração do grau de utilização (GU) e do Grau de Eficiência das Explorações (GEE), que ainda têm como base os dados da agropecuária brasileira de 1975. Ou seja, conforme assinala Teixeira (2011, p. 1), "no Brasil, a grande propriedade produtiva é assim classificada quando se observa os índices de rendimentos agropecuários de 35 anos atrás," que são, evidentemente, muito inferiores aos índices atuais de produtividade em virtude da utilização massiva de adubos, fertilizantes, herbicidas e novas técnicas de plantio.

Outra questão a ser enfrentada é a aquisição de terras em território nacional por parte do capital estrangeiro. Exemplo dessa prática é a aquisição de terras com vistas à produção de etanol, soja, milho, enfim, de culturas ligadas à demanda por agroenergias, alimentos e matérias-primas por parte do capital bancário e financeiro, tradicionalmente avesso à imobilização de recursos e correlata perda de liquidez. Segundo Sauer e Leite, a partir de estudo do Banco Mundial, a demanda mundial por terras tem sido enorme, especialmente de 2008, em diante tornando a disputa territorial um fenômeno global: "a transferência de terras agricultáveis era da ordem de 4 milhões de hectares por ano antes de 2008; só entre outubro de 2008 e agosto de 2009, foram comercializados mais de 45 milhões de hectares, sendo que 75\% destes na África e outros 3,6 milhões de hectares no Brasil e Argentina." Ainda com os autores, observamos que os Investimentos Diretos Estrangeiros (IEDs) no setor primário brasileiro passaram de 2,4 bilhões de dólares para 13,1 bilhões de dólares entre 2002 e 2008, representando uma alta de $445 \%$. Trata-se de uma nova fase, ampliada, da estratégia de adquirir um fator que será com certeza escasso num futuro próximo, sendo que, evidentemente, a especulação imobiliária também está em jogo: já se verifica no Brasil, principalmente nas "novas" fronteiras destinadas à monocultura da soja e da cana-de-açúcar dos estados de Tocantins, Goiás, Mato Grosso do Sul e Minas Gerais, 33\% de majoração nos preços das terras, o que encarece sobremaneira qualquer política de desapropriação da terra com vistas a uma reforma. $\mathrm{O}$ aparente paradoxo dessa estratégia é o fato de que as formas mais evoluídas de valorização do valor, imiscuídas no circuito D-D', subvertem o tempo histórico e retomam uma secular prática da especulação imobiliária, que tem acompanhado a história do capitalismo nos últimos trinta anos, qual seja, a especulação imobiliária. 
Exemplo dessa estratégia é a atuação do banqueiro George Soros. Segundo matéria de outubro de 2006, o homem que já especulou contra o Banco da Inglaterra, contra quase todas as moedas da Ásia e contra o próprio Brasil, em 2002, agora está investindo no agronegócio nacional. Esse senhor de 76 anos, cuja fortuna é estimada em 7,2 bilhões de dólares, acaba de adentrar o time de bilionários estrangeiros que está apostando no etanol brasileiro. Assim como Bill Gates, dono da Microsoft, e os meninos do Google, Larry Page e Sergey Brin, Soros se entusiasmou com o combustível verde. Ele participa do projeto de construção de três usinas de açúcar e álcool em Mato Grosso do Sul. Valor do empreendimento: 900 milhões de dólares. Juntas, as três unidades irão processar 11 milhões de toneladas anuais e produzir 1 bilhão de litros de álcool. Além do etanol, a empresa do financista húngaro, a Adeco, atua também em algodão e café no país. "Quando tudo estiver funcionando, o faturamento das operações no Brasil poderá ser igualar ao da Argentina”, conta Marcelo Vieira, o principal sócio de Soros no Brasil. Calcula-se que as operações rurais de Soros na Argentina já alcancem um faturamento de US\$ 30 milhões ${ }^{15}$.

A maior estatal chinesa do setor de alimentos, a China National Agricultural Development Group Corporation, também é um exemplo da ofensiva do capital internacional sobre as terras brasileiras. Esta empresa opera em quarenta países, e 10 mil de seus 80 mil funcionários trabalham no exterior. A empresa detém 6 mil hectares na Tanzânia e criou negócios no setor de alimentos também na Guiné, no Benin, na Zâmbia e já entrou na Argentina e no Peru. Outras companhias chinesas também têm comprado terras em vários países com o mesmo objetivo: garantir à China produtos indispensáveis ao seu crescimento econômico e à urbanização de centenas de milhões de pessoas. Desde a última década o governo chinês vem aumentando os investimentos em recursos naturais de outros países. Até agora, seu avanço mais impressionante ocorreu na África, onde os investimentos em mineração e depois na compra de terras foram acompanhados de projetos de cooperação com os países hospedeiros, quase sempre pobres e com baixo grau de desenvolvimento. O passo seguinte na estratégia foi a negociação de projetos com vários governos latino-americanos ${ }^{16}$. Exemplo desta

15. Dinheiro rural. Disponível em: $<$ http://www.terra.com.br/revistadinheirorural/capa24.htm>. Acesso em: 29 ago. 2011.

16. China compra terras no Brasil. Disponível em: $<$ http://www.estadao.com.br/noticias/impresso, china-compra-terras-no-brasil,589697,0.htm>. Acesso em: 29 ago. 2011. Outro exemplo de ofensiva às 
ofensiva do capital internacional sobre as terras brasileiras é a estratégia adotada pela CNADC (estatal chinesa de desenvolvimento agrícola), que anunciou em 2011 um investimento de 7 bilhões de dólares destinados à participação em projetos de expansão de lavouras de grãos no estado de Goiás com uma área estimada de 2,4 milhões de hectares destinada à produção de soja que será exportada para a China ${ }^{17}$. Cabe salientar que este país vem consolidando ao longo dos últimos anos uma base internacional de fornecimento de matérias-primas e alimentos a partir da Austrália, Indonésia, países do continente africano e América Latina, destacando-se o fato de que $93 \%$ do capital investido no Brasil em 2010 é proveniente de empresas estatais centrais (State-Owned enterprise).

Para além das condicionantes internacionais, que impõem uma reprimarização à economia brasileira, existem condicionantes internos que rechaçam a possibilidade de uma reforma agrária abrangente. Neste plano, os sucessivos governos brasileiros, a despeito de uma suposta maior aproximação do governo de Luíz Inácio Lula da Silva com a causa da reforma agrária, tem perpetuado uma situação fundiária que pouco se modificou nos últimos anos. Em 2009, $0,91 \%$ das propriedades, referindo-se àquelas com mais de mil hectares, respondiam por $44,42 \%$ da área ocupada, ao passo que as propriedades com menos de dez hectares ocupavam tão somente $2,36 \%$ da área, revelando o alto grau de concentração da terra neste país ${ }^{18}$. Outro indicador é o índice de Gini aplicado à concentração de terras: em 1967 esse índice perfazia 0,836, evoluindo para 0,854 em 2006.

O fato é que historicamente, seja em governos autoritários e militares, seja em governos marcados pela democracia eleitoral (a que nos resta), a estrutura da propriedade da terra pouco se alterou no Brasil nos últimos cinquenta anos. O gráfico abaixo demonstra que os diferentes perfis de propriedade da terra sofreram pequenas alterações entre 1960 e 2006, revelando que, para além de uma opção do governo atual, a não realização de uma reforma fundiária e agrária mais profunda vem se perpetuando como uma política de Estado. Após o

\footnotetext{
terras agricultáveis brasileiras é a empresa Hyundai, cuja atuação não se restringe apenas ao ramo automotivo. Segundo afirmou o diretor da empresa no Brasil, Gi Seob Kim, a Hyundai hoje atua na produção de navios de carga, extração de minérios e gasodutos, além do agronegócio. A busca por investimentos nesta última é realizada hoje na Rússia e no Brasil, especialmente para a produção de soja no estado do Piauí.

17. Disponível em: <http://www.cebc.org.br/sites/500/521/00001676.pdf>. Acesso em 30 ago. 2011.

18. Censo Agropecuário do IBGE 2006, divulgado em 2009.
} 
fim da ditadura militar e a "democratização" da cena política nacional em 1985, seria de se esperar que as forças populares e com projetos sociais mais equitativos ocupassem espaços de decisões e viabilizassem a reforma. Em certa medida, essa foi a tentativa no Plano Nacional de Reforma Agrária de 1985 e na Constituição Federal de $1988 .{ }^{19}$ Entretanto, com a subsequente adesão ao modelo neoliberal e a correlata erosão da cidadania, o que vimos foi justamente o contrário: apesar do aumento da porcentagem de terra cultivável disponível, de $26,7 \%$ do território nacional para $31,3 \%$ entre 1980 e 2010, o que se verificou foi a manutenção da desigualdade, da concentração da terra e dos perfis de propriedade abaixo demonstrados:

Gráfico $1 \%$ Perfis de propriedade da terra entre 1960 e 2006

propriedades acima de 1.000 hectares

propriedades entre 10 e 100 hectares propriedades entre 100 e 1.000 hectares

propriedades com menos de 10 hectares

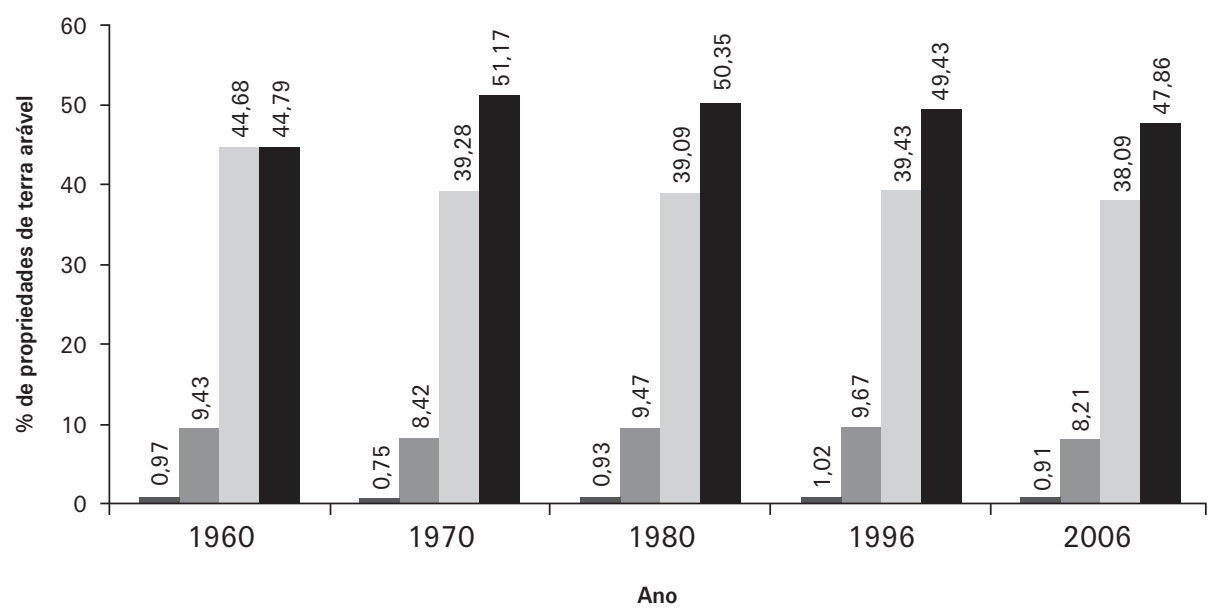

Fonte: www.sidra.ibge.gov.br

19. Artigo 184: “Cumpre à União desapropriar por interesse social, para fins de reforma agrária, o imóvel rural que não esteja cumprindo a sua função social, mediante prévia e justa indenização em títulos da dívida agrária, com cláusula de preservação de valor real, resgatáveis no prazo de até vinte anos, a partir do segundo ano de sua emissão, e cuja utilização será definida em lei”. 
Seria de se esperar, num país onde a reforma agrária constituísse parte de um projeto estrutural de transformação fundiária, que as proporções acima apontadas apresentassem sensíveis alterações, uma vez que se trata de uma longa série histórica (quase cinquenta anos). Contudo, o caso brasileiro, quando observado no longo prazo, indica uma inflexibilidade no que se refere à participação percentual das faixas de propriedade sobre a terra agricultura. As propriedades com menos de dez hectares, nesse período, perfizeram aproximadamente metade do total, reduzindo em 2006 para 47,86\%, quando seria de se esperar, caso a opção tivesse sido a reforma agrária, que justamente esse perfil aumentasse a sua participação percentual à custa da redução dos demais perfis de propriedade. Estes dados nos levam a pensar que a mudança na estrutura fundiária não está colocada como projeto no governo e na sociedade brasileira a longo prazo. A opção parece ser a de "congelar" a estrutura fundiária com políticas de compensação que garantam a viabilidade das pequenas propriedades, mas que não as ampliem, ou as ampliem até o ponto em que não ameacem a preponderância absoluta da grande propriedade ligada ao agronegócio de exportação. Políticas como o Pronaf - Programa de Fortalecimento da Agricultura Familiar, o Ater - Assistência Técnica e extensão Rural, o Bolsa Verde (que inclui um benefício de R \$ 300,00 mensais, sementes e cisternas), e o próprio Bolsa-Família, que acaba abarcando parcelas da população rural, são exemplos dessa estratégia. Estas políticas compõe o que Delgado (2005) chamou de "ajustamento constrangido," pois não propõem nenhuma saída e são destinadas à uma minoria de pequenos produtores familiares e assentados.

\section{Considerações finais}

A atual presidente Dilma Rousseff tem utilizado justamente esses mecanismos no combate à pobreza rural, que, segundo seu entendimento, afeta de maneira mais brutal o sistema econômico do que a atual configuração da posse da terra. A lógica predominante tem sido justamente a de suprir uma renda às famílias até que elas tenham condições de se integrar à estrutura produtiva e ao mercado ${ }^{20}$. Esta política se explica, sob nosso entender, por alguns fatores:

20. CARVALHO Ricardo; ARGEGGE Soraya. Extrema-unção. Revista Carta Capital. 29/7/2011. 
a) ausência de perspectivas de mudanças no modelo econômico;

b) os limites fiscais e estruturais de nossa economia e a correlata necessidade (crescente) de geração de superávits via exportação de commodities viáveis apenas em grandes escalas (latifúndios), sobretudo nas lavouras ligadas à produção de biocombustíveis ${ }^{21}$;

c) a elevação abrupta do preço da terra, o que encarece a reforma agrária;

d) a força política da bancada ruralista e a defesa contundente que o governo brasileiro tem feito dessa forma de inserção absolutamente especializada na economia mundial exemplificam na aprovação do novo Código Florestal, que abre brechas para a manutenção e a ampliação dos desmatamentos;

e) a falta de mobilização da maior parcela da população brasileira, pois hoje apenas 15,6\% está alocada nos setores agrícolas, sendo que apenas $11 \%$ da força de trabalho está alocada na zona rural, indicando que o alto grau de urbanização da sociedade brasileira dificulta a universalização da bandeira da reforma agrária;

f) com louváveis exceções, como o MST e a Via Campesina, é baixíssimo o grau de mobilização política acerca desta questão.

Neste quadro, não é de se estranhar que o crédito para assentamentos tenha se reduzido consideravelmente entre 2008 e 2011 (de 1,6 bilhão de reais para 900 milhões), bem como o desembolso de recursos para a obtenção de áreas para a reforma agrária, que foram reduzidos de 1,92 bilhão em 2005 para 482 milhões de reais em 2011. Aliás, o governo tem desembolsado valores inferiores aos aprovados na LOA - Lei de Orçamento Anual, como no caso da concessão do crédito, onde foram aprovados, para 2011, 900 milhões de reais, dos quais apenas 30 milhões foram efetivamente gastos (Carvalho; Argegge, 2011). Não é de se estranhar, nestes termos, que o número de famílias assentadas tenha se reduzido consideravelmente nos últimos anos, como podemos observar no gráfico a seguir:

21. Estima-se que o Brasil dispõe de 64,7 milhões de hectares aptos ao cultivo de cana-de-açúcar. Cf. Nakatani, Faleiros, Vargas. O Brasil e os biocombustiveis. 2011. 
Gráfico 2 Famílias assentadas pelo Incra

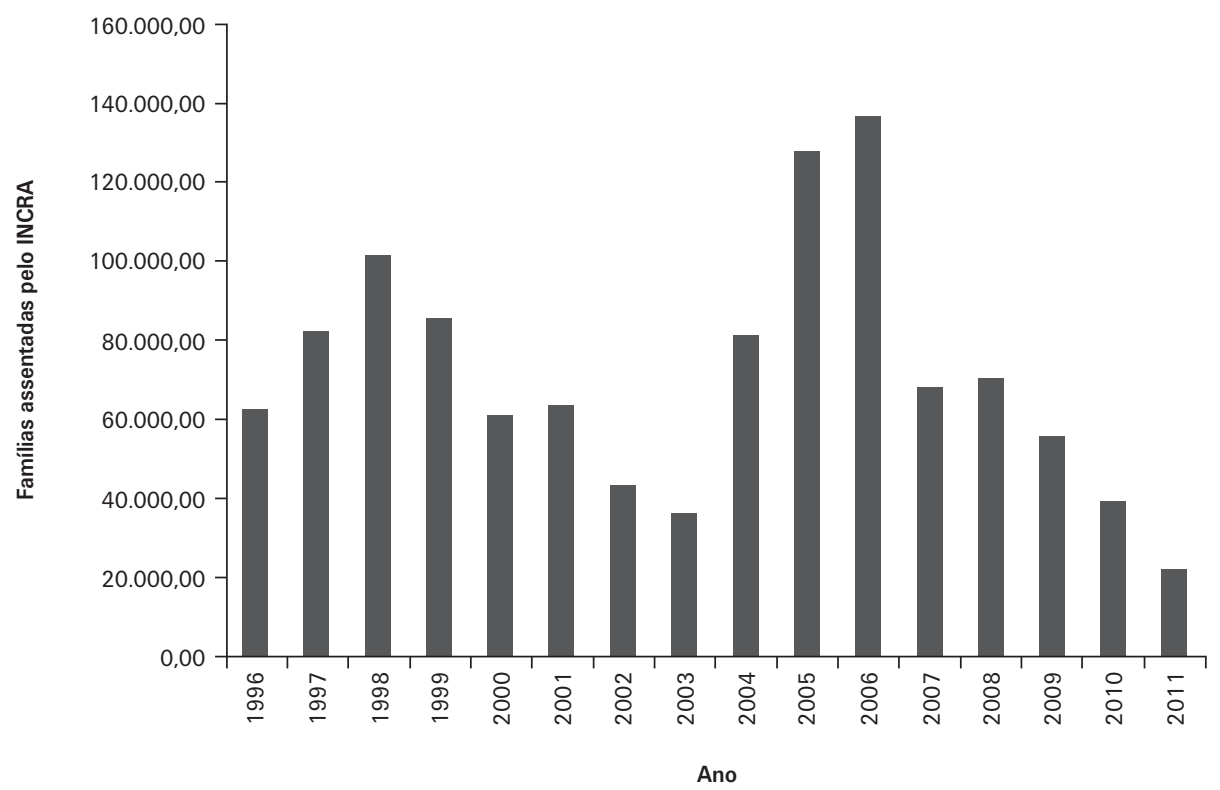

Fonte: http://www.incra.gov.br/index.php/reforma-agraria-2/questao-agraria/ numeros-da-reforma-agraria/file/1148-familias-assentadas. Acesso em: 27/4/2012.

Recebido em 31/3/2012 - Aprovado em 13/4/2012

\section{Referências bibliográficas}

BASTOS, Elide Rugai. As ligas camponesas. Petrópolis: Vozes, 1984.

CANO, Wilson. Raizes da concentração industrial em São Paulo. 4. ed. Campinas: IE/Unicamp, 1998.

CARVALHO, Ricardo; ARGEGGE, Soraya. Extrema-unção. Revista Carta Capital, 2011. COSTA, Edmilson. A política salarial no Brasil. São Paulo: Boitempo editorial, 1997.

DELGADO, Guilherme. A questão agrária no Brasil, 1950-2003. In: JACCOUD, Luciana. Questão social e políticas sociais no Brasil contemporâneo. Brasília: Ipea, 2005. p. 51-90. 
DE NEGRI, Fernanda; ALVARENGA, Gustavo Varela. A primarização da pauta de exportações no Brasil: ainda um dilema. Brasília. Boletim Radar, n.11, dez. 2010.

FALEIROS, Rogério Naques. Fronteiras do café: fazendeiros e "colonos" no interior paulista (1917-1937). Bauru: Edusc/Fapesp, 2010.

. Homens do café: Franca 1880-1920. Ribeirão Preto: Holos Ed., 2008.

FERNANDES, Florestan. A revolução burguesa no Brasil. Ensaio de interpretação sociológica. 5. ed. São Paulo: Globo, 2006.

. Sociedade de classes e subdesenvolvimento. 5. ed. São Paulo: Global Editora, 2008.

FURTADO, Celso Monteiro. Formação econômica do Brasil. 34. ed. São Paulo: Companhia das Letras, 2007.

GUIMARÃES, Alberto Passos. Quatro séculos de latifúndio. Rio de Janeiro: Paz e Terra, 1968.

JEZUS, Luís Alberto. A questão agrária no Brasil. In: MARQUES, Rosa Maria; FERREIRA, Mariana Ribeiro Jansen (Org.). O Brasil sob a nova ordem: a economia brasileira contemporânea. Uma análise dos governos Collor a Lula. São Paulo: Saraiva, 2010.

MARTINS, José de Souza. Expropriação \& violência: a questão política no campo. São Paulo: Hucitec, 1982.

MENDONÇA, Sônia Regina de. A classe dominante agrária: natureza e comportamento — 1964-1990. In: STÉDILE, João Pedro (Org.). A questão agrária no Brasil. São Paulo: Expressão Popular, 2006. v. 5.

MOTTA, Márcia; ZARTH, Paulo (Orgs.). Formas de resistência camponesa: visibilidade e diversidade de conflitos ao longo da história. São Paulo/Brasília: Unesp/Ministério do Desenvolvimento Agrário, 2008.

NAKATANI, Paulo; FALEIROS, Rogério Naques; VARGAS, Neide César. O Brasil e os biocombustíveis. Vitória, 2011. (Mimeo.).

NOVAIS, Fernando. Portugal e Brasil na crise do antigo sistema colonial. 7. ed. São Paulo: Hucitec, 2001.

OLIVEIRA, Francisco. Crítica à razão dualista. São Paulo: Boitempo, 2003.

PRADO JR. Caio. A revolução brasileira. São Paulo: Brasiliense, 1972.

SACHS, Ignacy; WILHEIM, Jorge; PINHEIRO, Paulo Sérgio (Org.). Brasil: um século de transformações. São Paulo: Companhia das Letras, 2001.

SAUER, Sérgio; LEITE, Sérgio Pereira. A estrangeirização da propriedade fundiária no Brasil. Disponível em: http://www.cptpe.org.br/index.php/publicacoes/noticias/2-noticia/ 2686-a-estrangeirizacao-da-propriedade-fundiaria-no-brasil-.html. Acesso em: 29 ago. 2011. 
SILVA, José Graziano. O novo rural brasileiro. Campinas: Unicamp, IE, 2002.

SILVA, Lígia Osório. Terras devolutas e latifúndio. Efeitos da Lei de 1850. 2. ed. Campinas: Editora da Unicamp, 2008.

SIMONSEN, Roberto C. História econômica do Brasil. 4. ed. São Paulo: Cia. Editora Nacional, 1957.

SODRÉ, Nelson Werneck. Formação histórica do Brasil. 10. ed. Rio de Janeiro: Civilização Brasileira, 1979.

STÉDILE, João Pedro; FERNANDES, Bernardo Mançano. Brava gente: a trajetória do MST e a luta pela terra no Brasil. São Paulo: Perseu Abramo, 1996.

STÉDILE, João Pedro (Org.). A questão agrária no Brasil: o debate tradicional 1500-1960. São Paulo: Expressão Popular, 2005.

TAVARES, Maria da Conceição. Da substituição de importações ao capitalismo financeiro. Rio de Janeiro: Zahar Editores, 1977.

Império, território e dinheiro. In: FIORI, José Luís (Org.). Estados e moedas no desenvolvimento das nações. Petrópolis: Vozes, 1999.

TEIXEIRA, Gerson. Agravamento do quadro de concentração e terra no Brasil? Boletim Dataluta, Brasília, jul. 2011.

WELCH, Clifford Andrew. A semente foi plantada: as raízes paulistas do movimento sindical camponês no Brasil, 1924-1964. São Paulo: Expressão Popular, 2010. 